\title{
Análisis y comentarios a la conciliación extrajudicial : la experiencia del IPRECON (Instituto Peruano de Resolución de Conflictos, Negocia- ción y Mediación)
}

José Zegarra Pinto

A partir de la entrada en vigencia de la Ley de Conciliación Extrajudicial (Ley No 26872) y su Reglamento (D.S. No 001-98-JUS), mucho se ha escrito acerca de las ventajas y beneficios que trae consigo el poder contar con una legislación de esta naturaleza. Dichas opiniones merecen nuestro más absoluto respeto, y es por eso que desde aquí las felicitamos. Pero tal como sucede en otros casos, una vez que esta norma ha empezado a aplicarse, se han advertido ciertas falencias u omisiones en las que ha incurrido nuestro legislador.

A través del siguiente trabajo pretendemos alcanzar un doble objetivo: de primera intención buscamos describir de una manera breve y didáctica el proceso conciliatorio regulado por la normativa antes citada. Asimismo traeremos a discusión algunos temas que consideramos de suma importancia. El segundo objetivo parte de nuestro deseo por que se inicie un análisis y debate más profundo sobre la Ley de Conciliación Extrajudicial y su Reglamento. Toda esta exposición será realizada a partir de la experiencia que hemos logrado adquirir en el Centro de Conciliación Extrajudicial del IPRECON. ${ }^{1}$

1 El Centro de Conciliación Extrajudicial del Instituto Peruano de Resolución de Conflictos, Negociación y Mediación (IPRECON) con sede en Lima, ha sido autorizado a funcionar mediante Resolución Ministerial No 279-98-JUS. En estos momentos el IPRECON cuenta con dos centros más, los cuales se encuentran ubicados en las ciudades de Arequipa y Trujillo. 


\section{El proceso conciliatorio}

\subsection{La solicitud de conciliación}

La Solicitud de Conciliación es aquel documento que nos va a permitir dar inicio al proceso de conciliación. La regla general será que todas aquellas personas que deseen contar con los servicios de un centro de conciliación o juzgado de paz que realice dicha actividad, deberán elaborar su respectiva solicitud. A través de la misma lo que se desea es obtener no solamente una correcta identificación de las partes en conflicto, sino también acceder a información que nos permita una adecuada descripción de los hechos que ocasionaron el surgimiento del conflicto. Según lo que se puede concluir del estudio de nuestra normativa, son básicamente dos las maneras por las cuales los interesados pueden obtener la aludida Solicitud de Conciliación: de manera escrita y de manera verbal.

\subsubsection{De manera escrita.}

Conforme a lo señalado por nuestro Reglamento, la solicitud deberá presentarse por escrito y contendrá al menos una determinada información. ${ }^{2}$ En líneas generales, lo que se desea con dicho documento es identificar todos los elementos que han intervenido en la aparición del asunto conflictivo. De la misma manera, se deberá adjuntar tantas copias de la solicitud y sus anexos ${ }^{3}$ como partes se necesitan invitar a la $\mathrm{Au}$ diencia de Conciliación.

\subsubsection{De manera verbal}

Para este caso nuestro legislador ha previsto que tanto los centros de conciliación como los juzgados de paz que realicen esta labor, deberán contar con formatos de solicitudes de conciliación. Esto permitirá no sólo hacer más ágil el inicio de dichos procedimientos, sino también

2 Decreto Supremo 001-98-JUS, artículo $12^{\circ}$.

3 Tanto la Ley como el Reglamento nos señalan que basta el uso de copias simples para iniciar el procedimiento conciliatorio. La única excepción la constituye lo establecido en el artículo $22^{\circ}$ del Reglamento, el cual refiriéndose a los representantes de personas jurídicas establece que: “[...] La representación se acredita con la copia notarialmente certificada del documento donde conste el nombramiento, debidamente inscrito.». 
beneficiar a todas aquellas personas que no se encuentran en posibilidad de redactar un documento de esta naturaleza (analfabetos, invidentes etc.). Es conveniente hacer la precisión de que la recolección de datos y la elaboración de dicha solicitud estará bajo la responsabilidad del conciliador o del juez de paz letrado que conocerá del procedimiento.

Es pertinente resaltar el carácter personalísimo de la conciliación extrajudicial. Con esto deseamos advertir que solo podrán participar en dicho proceso las partes intervinientes en el conflicto. Como excepciones a la regla general tenemos: las personas que por ley deban actuar a través de representante legal (menores de edad, interdictos etc.), las personas jurídicas y las personas naturales domiciliadas en el extranjero.

Cabe agregar que la norma permite que la solicitud de conciliación contenga una propuesta de acuerdo por parte de quien solicita la conciliación (solicitante), lo cual en muchos de los casos podría constituirse como un excelente referente para iniciar el proceso.

En el caso de los centros de conciliación del IPRECON, hemos optado de primera intención por ser nosotros los que elaboramos la solicitud de conciliación. Los actuales momentos nos permiten concluir que no sólo debemos actuar como meros administradores de procesos, sino también cooperar con las partes para conseguir la tan ansiada solución al conflicto.

\subsection{Designación del conciliador}

Una vez que el solicitante posea su respectiva solicitud de conciliación, se puede dar inicio al proceso. Así, recepcionado dicho documento por parte del centro de conciliación, en el día se procederá a designar al respectivo conciliador. Esta actividad se encuentra a cargo del Director del centro de conciliación quien, en atención a las características del conflicto, procederá a la elección. Además de su designación, se le notificará al conciliador la identificación de las partes y la materia por la cual se le ha convocado.

\subsection{Notificación al solicitante de la designación del conciliador}

Al día siguiente de recibida la solicitud, el centro comunicará al solicitante la identificación de la persona que ha sido designada como conciliador extrajudicial para su conflicto. Asimismo, se le hará saber que 
en caso de no estar conforme con la designación efectuada, tendrá la posibilidad de objetarla tomando como base los causales de impedimento, recusación y abstención establecidos en el Código Procesal Civil. Esta última actividad deberá efectuarse dentro del día útil siguiente a la recepción de la aludida comunicación. Por otro lado, una vez que el solicitado conoce de la identidad del conciliador, tiene éste a su vez la oportunidad de objetar dicha designación hasta 24 horas antes de celebrarse la audiencia de conciliación. ${ }^{4}$

En esta misma fecha, es decir al día siguiente de recibida la solicitud, el centro entregará al conciliador toda información que haya sido puesta a disposición del centro es decir la solicitud y sus respectivos anexos. De la misma manera el conciliador puede, sobre la base del análisis que realice en ese día, manifestar su decisión de no continuar con su participación en dicho procedimiento de conciliación.

\subsection{Notificación a las partes de la invitación a conciliar}

Al tercer día útil posterior a la recepción de la solicitud y de no haber ninguna clase de objeción con respecto a su participación en el procedimiento, el conciliador notificará a las partes la invitación a conciliar. Cabe agregar que entre la notificación y la realización de la Audiencia debe existir al menos 2 (dos) dias útiles.

Es pertinente mencionar que mediante Resolución Ministerial No 032-98-JUS, se aprobaron una serie de formatos de invitación y actas de conciliación. ${ }^{5}$ Dichos documentos modelos deberán ser utilizados por todos aquellos entes que se encuentren autorizados legalmente para ejercer actividad conciliatoria extrajudicial. La no observancia de las formalidades exigidas legalmente produce la inmediata nulidad del acta de conciliación emitida.

Conforme advertimos al inicio de este trabajo, la práctica nos ha permitido conocer determinados casos que podrían catalogarse como omisiones de nuestra legislación. Así, se han llegado a presentar algunos supuestos que pasamos a exponer:

El primero se encuentra referido al hecho de que el solicitado se niegue a recibir la notificación. Si bien el responsable de notificaciones 
procedía a redactar el respectivo informe tal como señala el Reglamento, el inconveniente venía a ser el siguiente: ¿cómo concluir formalmente dicho procedimiento si es que legalmente no existe un tipo de acta para esta clase de supuesto? Finalmente, el problema que se generaba era que en nuestros registros se encontraría asentado el ingreso de una solicitud pero, por otro lado, no se encontraría asentada ninguna acta de conciliación que pusiera fin a dicho procedimiento.

Otro caso lo advertimos cuando el notificador nos comunicaba que la dirección señalada en la solicitud de conciliación no coincidía con la dirección real de la parte solicitada. Por lo general, dichos defectos eran fácilmente subsanables, pero es aquí donde surge la interrogante: ¿cómo intentar convalidar esa clase de errores si es que en la Ley de Conciliación y su Reglamento no existe ningún proceso que nos permita realizar dicha subsanación? Siempre hemos sido partícipes de que la Ley de Conciliación debería regular una suerte de proceso que permita a los solicitantes subsanar cualquier clase de omisión o error en el que se hubiese incurrido al momento de redactar su solicitud.

\subsection{La audiencia de conciliación}

Continuando con nuestra exposición, pasamos a exponer sobre la etapa que, según nuestro punto de vista, es la más importante dentro del proceso conciliatorio: la audiencia.

A excepción de la conciliación en temas de violencia familiar, no existe ninguna clase de articulado que señale alguna actividad especial para el conciliador y las partes que intervienen en un proceso de conciliación. Dado que el tema de conciliación en violencia familiar es sumamente importante y extenso, nos reservamos el comentario del mismo para otra oportunidad.

De llegar a contarse o no con la presencia del conciliador y de las partes intervinientes en el conflicto, pueden darse los siguientes supuestos:

1. Las partes llegan a un acuerdo total y se da por concluido el proceso.

2. Las partes llegan a un acuerdo parcial y se da por concluido el proceso.

3. Las partes no se llegan a poner de acuerdo y se da por concluido el proceso. 
4. Una de las partes no asiste a 2 (dos) sesiones de manera seguida o alternada y se da por concluido el proceso.

5. Las partes no asisten a una sesión y se da por concluido el proceso.

Conforme se señala en el artículo $15^{\circ}$ del Reglamento, los supuestos antes señalados son los que pueden llegar a dar por concluido un proceso de conciliación. Asimismo, se puede llegar a presentar otra clase de situaciones como, por ejemplo, la siguiente:

¿Qué hacer cuando el que no asiste es el conciliador? Una situación de esta naturaleza no debería escapar a la consideración de ningún centro de conciliación. Cabe advertir que, al respecto, nuestro legislador no ha previsto ninguna clase de paliativo o consecuencia. La duda surge por el lado de qué hacer: ¿se debe dar por concluido el proceso?, ¿se debe volver a citar a las partes? A manera de propuesta, creemos que se debería permitir al secretario general del centro, con previa aceptación de las partes, asumir la conducción de dicha audiencia.

Continuando con nuestra exposición, cabe agregar que independientemente del resultado del proceso, se deberá emitir un acta de conciliación, la cual a su vez deberá ser registrada en el Libro de Registro de Actas del centro (original). Por otro lado, a cada una de las partes se le entregará copia certificada de dicho documento. La certificación de dichas actas deberá estar a cargo del secretario general del centro de conciliación. ${ }^{6}$

Es pertinente acotar que cada vez que alguna de las partes intervinientes en el procedimiento de conciliación desee obtener nuevas copias certificadas del acta, deberá recurrir al centro de conciliación y verificar en el Archivo de Actas el número de folio en el cual se encuentra registrado dicho documento.

A manera de hacer más didáctica la información expuesta, al final del trabajo anexamos un esquema del proceso conciliatorio.

5 Publicado en el diario oficial «El Peruano» el 4 de marzo del año 1998.

6 Resolución Ministerial 081-98-JUS - Reglamento Tipo de Centros de Conciliación (artículo 50). 


\section{Algunos temas para comentar}

\subsection{Conciliación extrajudicial «inmediata»}

En reiteradas oportunidades se nos han presentado casos en los cuales dos o más partes en conflicto concurren al centro, con el fin de llegar a un acuerdo en el menor período de tiempo posible. Hasta aquí, esto no tendría nada raro o especial, pero el detalle radica en que dichas partes lo que en realidad desean es que se realice una audiencia de conciliación en ese preciso instante, en atención a que quieren arribar a una solución de una vez por todas y buscando además el respaldo legal que brinda el acta de conciliación extrajudicial.

Es aquí donde surge la disyuntiva: por un lado tenemos un proceso conciliatorio que implica respetar toda una serie de plazos y actos; y por otro nos encontramos con dos o más partes que buscan, a través de la conciliación extrajudicial, poseer un documento que le de fin a su controversia en un período de tiempo que es inclusive mucho menor al señalado legalmente.

Si bien desde la emisión de la ley siempre se ha resaltado el hecho de que la conciliación extrajudicial implica contar con plazos sumamente cortos, muy por el contrario, parecería que para el caso planteado, dichos plazos vendrían a ser una suerte de obstáculo para la búsqueda de la tan ansiada solución.

Cabe señalar que básicamente fueron dos los motivos que dieron lugar a la emisión de una norma de esta naturaleza, los mismos que llegaron a traducirse en nuestros tan conocidos principios de celeridad y economía. Era necesario hacer referencia a estos principios dado que nos permitirá dar una adecuada opinión al caso planteado.

En atención a lo expuesto, somos de la idea que la norma debió establecer la realización de un proceso de conciliación inmediato. Si partimos del supuesto de que la dación de esta ley tuvo como principal móvil buscar un proceso rápido, económico y eficaz de resolución de conflictos, no comprendemos por qué no se llegó a contemplar un supuesto de esta naturaleza. Conforme podrán advertir, la no observancia de los plazos antes indicados puede llevar a que el centro sea sancionado de dos maneras: multa o desautorización de funcionamiento, y en este último cabe la posibilidad que posteriormente se disponga 
su cierre definitivo. ${ }^{7}$ Para finalizar debemos manifestar que si bien el centro de conciliación puede ser sancionado, el acta de conciliación seguirá gozando de su carácter de título de ejecución.

\subsection{Solicitudes de conciliación «maliciosas»}

En un par de oportunidades hemos tenido la mala fortuna de tramitar dos procedimientos en los cuales ha ocurrido una situación especial. Una vez citadas las partes a la audiencia de conciliación respectiva y llegado el día y la hora para el inicio de la misma, nos dábamos con la sorpresa que solo concurría el solicitado a conciliar y, aunque parezca extraño, no se presentaba el solicitante. Es decir, el supuesto interesado en llegar a una solución se ausentaba y esto se repetía en la segunda sesión. Como es de esperarse, dicho procedimiento llegaba a concluir por inasistencia de una de las partes a dos sesiones consecutivas. Toda esta situación lo único que llegaba a producir era un mayor nivel de conflictividad, dado que exacerbaba aun más los ánimos de las partes en conflicto.

Somos de la opinión que lo más adecuado hubiese sido establecer sanciones para el solicitante malicioso, en atención a la mala fe mostrada y a su conducta poco resolutiva, la cual no solo perjudica a la parte solicitada sino también genera que el centro de conciliación invierta sus esfuerzos en procesos que no han sido planteados de buena fe.

\subsection{Conclusión del proceso por el conciliador}

Esta última reflexión parte del siguiente cuestionamiento: ¿por qué la persona que dirige el proceso de conciliación no puede ponerle fin al mismo? Esta es una pregunta que la venimos haciendo por largo tiempo, inclusive antes que nos constituyéramos como centro de conciliación. Ante esta interrogante, de primera impresión se podría pensar que se trata de una gran omisión de la norma ya que se no se contempla expresamente un supuesto de esta naturaleza.

Para tener una idea más clara de lo que deseamos exponer, imaginémonos el siguiente ejemplo: durante la primera sesión de una audien-

7 Resolución Ministerial No $174-98$-JUS, artículo $26^{\circ}$, inciso b) y artículo $30^{\circ}$, inciso b). 
cia de conciliación ambas partes acuerdan que previamente a la segunda sesión, se reunirán para esbozar una solución al conflicto. Pero, la negociación entre las partes resulta infructuosa y se dan por finalizadas las conversaciones entre ellas. Cabe señalar que independientemente a todo esto, tenemos un proceso de conciliación pendiente el cual inclusive tiene prevista una próxima sesión, la misma que deberá realizarse forzosamente. Esto último nos parece de lo más absurdo. Consideramos que en su rol de facilitador del diálogo y el entendimiento, se debería establecer expresamente que el conciliador tuviese la facultad de poner fin al proceso de conciliación.

A manera de respuesta, creemos que todo esto puede solucionarse de la siguiente manera: cada vez que se llegue a verificar una situación como la antes descrita, el conciliador puede poner fin al proceso debido a: «[...] falta de acuerdo entre las partes». Consideramos que aun cuando tales hechos se han logrado verificar fuera del centro de conciliación, esto no le impediría al conciliador ponerle fin al mismo.

\subsection{Conciliador unipersonal}

De primera intención debemos decir que si bien este supuesto no se encuentra contemplado en nuestra legislación sobre conciliación, al parecer podría llegar a ser implementado si es que se produce una modificación.

La primera pregunta que estará surgiendo en estos momentos es: ¿qué es un conciliador unipersonal? Se denominará conciliador unipersonal a toda persona que ejerza actividad conciliadora con la característica que tendrá una doble función: abogado y conciliador. Asimismo, deberá realizar su labor contando con una infraestructura igual a la de un centro de conciliación. Finalmente, de lo que se trata es de una sola persona efectuando conciliaciones extrajudiciales.

Respecto a este tema, es preciso que manifestemos nuestro total desacuerdo con la instauración de una figura de este tipo. Fundamentamos nuestra opinión sobre la base de los siguientes argumentos:

\subsubsection{Administración del centro de conciliación}

Como es de esperarse, la labor de administración del centro se tornará algo complicada para este tipo de conciliadores, dado que tendrán la obligación de cumplir múltiples funciones: director del centro, se- 
cretario general, conciliador, etc. Tener un correcto control de dicha carga de trabajo será muy difícil si es que no se cuenta con el apoyo humano y logístico suficiente. Es lógico, por tanto, que sean los centros de conciliación los que se encuentran en la posibilidad de realizar la conciliación, de acuerdo a las expectativas generadas sobre esta institución.

\subsubsection{Mayor capacitación y experiencia}

Somos de la opinión, si es que se legisla un supuesto de esta naturaleza, que todos los conciliadores unipersonales deberán ser profesionales que gocen de una connotada experiencia en el campo de la resolución de conflictos. Además, y esto es lo más importante, deberán tener comprobada especialización en el campo de la conciliación y específicamente en la práctica de la misma.

En el IPRECON siempre hemos manifestado nuestra preocupación por el hecho de que la capacitación exigida por nuestra legislación a los futuros conciliadores extrajudiciales es insuficiente. Una capacitación inadecuada, como es lógico, repercute negativamente en los servicios que se prestan a los usuarios del centro, lo que finalmente generaría un desprestigio de la institución de la conciliación. Entonces, con mayor razón nos preocupa la existencia de un profesional de este tipo. No se niega que podrían existir profesionales que posean las características que señalamos pero, a su vez, creemos que en la actualidad éstos serían muy pocos.

Cabe agregar que conforme señala nuestro legislador, todo conciliador deberá realizar cursos de actualización con el objetivo de acrecentar sus conocimientos y perfeccionar sus habilidades prácticas. Para este caso, nuevamente, el conciliador unipersonal tendría que recurrir a una entidad capacitadora o a un centro de conciliación que dicte este tipo de cursos. Como se puede advertir, finalmente todo nos lleva rumbo a la vía de los centros de conciliación.

\subsubsection{Supervisión}

Es lógico que de existir la posibilidad de ostentar un titulo de esta naturaleza, serán muchos los profesionales que decidirán convertirse en conciliadores unipersonales, hablamos de profesionales que ejercerán dicha función en la costa, sierra y selva de nuestro país. Esto nos parece que sería algo correcto y lógico pero por otro lado se podría generar un 
inconveniente de tipo físico dado que se tendría problemas para ejercer un efectivo control de esta clase de profesionales.

El ente encargado de dicha actividad, es decir la Secretaría Técnica de Conciliación, necesitaría contar con un elevado número de personas que de manera constante realicen labores de supervisión.

Entonces, si el conciliador unipersonal debe cumplir con todos los requisitos de un centro de conciliación, además de contar con un local de similares características, ¿por qué no seguir con la figura de los centros de conciliación tal cual lo señala la Ley No 26872?

Como comentario final al tema del conciliador unipersonal, consideramos que la idea en general de permitir que un mayor número de personas realice actividad conciliatoria es de lo más acertada. Pero, no compartimos que dicha aspiración llegue a forzar la institución de la conciliación creando figuras que a la larga traerán más complicaciones que aciertos. Al igual que cualquier tipo de proceso de cambio de concepciones o estructuras, la implementación de la conciliación, legalmente hablando, merece un período de consolidación. Es por todo lo expuesto que mantenemos la idea que debe ser a través de los centros de conciliación la manera como se tiene que trabajar el tema de la conciliación extrajudicial en nuestro país.

Antes de finalizar deseamos citar algunas ideas vertidas por Martha Oyhanarte, ${ }^{8}$ las cuales son pertinentes para los actuales momentos:

Es importante estimular a la mayor cantidad de personas en escuelas, centros comunitarios, asociaciones vecinales, empresas, a comprometerse a resolver posibles disputas usando la ayuda de un tercero imparcial. Este será el verdadero comienzo del cambio.

Es importante comenzar en el lugar que marca nuestra propia historia, sin copias estereotipadas de modelos ajenos.

Es importante aceptar que la mediación es una herramienta nueva, un sendero espiritual, una necesidad política, un desafío ético.

Con las reflexiones antes realizadas, no pretendemos restarle crédito a nuestra Ley de Conciliación Extrajudicial. Muy por el contrario, lo que buscamos es contribuir a su mejora para así incrementar aun más la inmensa gama de beneficios da la aplicación de la conciliación extrajudicial como medio alternativo de resolución de conflictos.

8 Marta Oyhanarte, "Los Nuevos Paradigmas y la Mediación" En: Mediación - una transformación en la cultura. Compiladores Julio Gottheil y Adriana Schiffrin. Colección Mediación. Argentina, Editorial Paidós, 1996. 

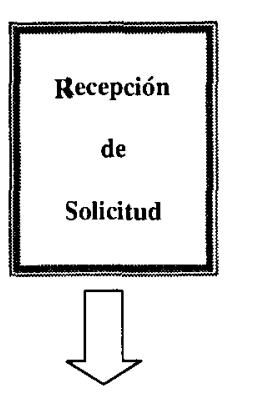

Designación del

Conciliador

(Dr. del Centro)

Art. 4 lit q) del

Rgto. del C. de C.
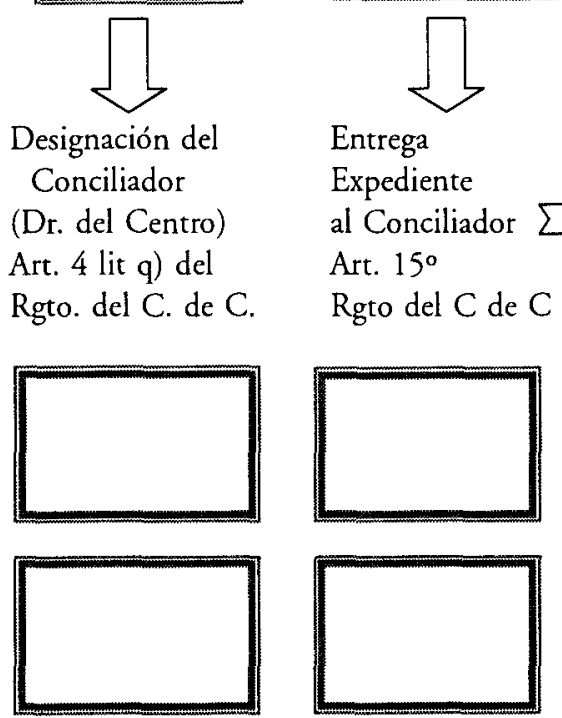

Entrega

Expediente

Art. $15^{\circ}$

Rgto del C de C

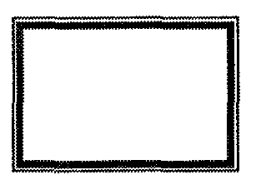

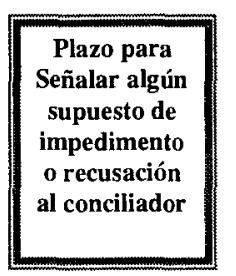
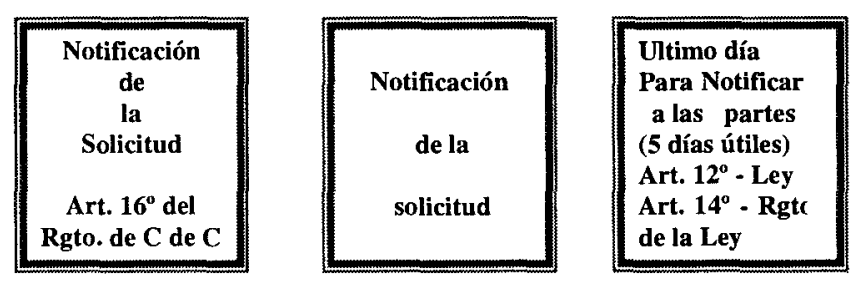

En el día manifestará si se

al Conciliador $\Sigma$

encuentra incurso en algún
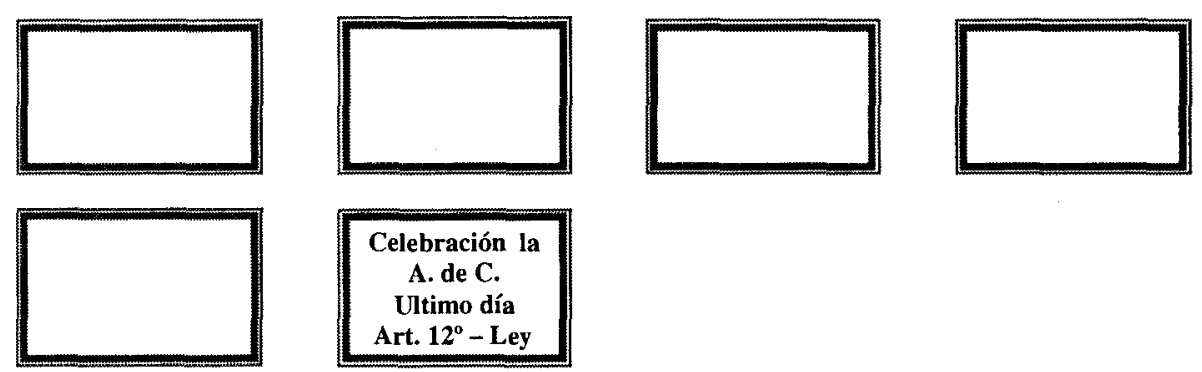

- Recusación: Hasta 24 horas antes de la celebración de la A. de C (Art. 38 ${ }^{\circ}$ del Reglamento de la Ley)- 230 de la Ley

- Entre la notificación y la Audiencia de Conciliación debe existir al menos dos (02) días útiles. (Art. 160 del Reglamento del C. de C.).

- Todos los plazos señalados son días útiles.

- La audiencia de conciliación debe celebrarse dentro del plazo de 30 días calendario contados a partir de la 1 ra notificación a las partes, el plazo puede ser prorrogado por acuerdo entre las partes (Art. $11^{\circ}-$ Ley) - Rev $12^{\circ}$ Ley. 